\title{
Europe plans concessions to kick-start Kyoto
}

Jim Giles, London

In a bid to activate the Kyoto protocol on climate change without the United States, negotiators from the European Union (EU) are planning to offer concessions to Japan at next month's meeting of the parties to the treaty in Bonn.

The protocol cannot come into effect until it is ratified by countries that together account for $55 \%$ of greenhouse-gas emissions from developed nations, as measured in 1990. Europe, including non-EU countries and Russia, accounts for about half of these emissions, but it would probably need the cooperation of Japan, which accounts for $8.5 \%$ of them, to reach the threshold and bring the treaty into effect.

Japan has previously said that it will not ratify the accord unless the United States also ratifies it. But the Europeans hope to persuade it to do so on the basis that the United States will eventually rejoin the process.

The EU's concessions were released on 11 June by Jan Pronk, the Dutch environment minister, who will chair talks on the protocol when they resume in Bonn next month.

The document alters the amount by which Japan's emission target can be reduced if the country changes its land-use patterns. The protocol commits most developed nations to overall cuts of between $5 \%$ and $8 \%$ on 1990 emission levels by 2012. Countries can earn reductions in their target by a variety of measures, such as planting new forests, which absorb carbon dioxide.

\section{Flavour switching}

The solar neutrino problem has been solved, according to researchers working at the Sudbury Neutrino Observatory (SNO) in Canada. Their results explain why physicists looking for neutrinos emitted by the Sun have detected between a half and a third as many particles as predicted.

The Sun mainly emits electron neutrinos, but the particles also come in two other 'flavours', known as tau and muon neutrinos. Neutrino detectors are primarily sensitive to electron neutrinos, which means the deficit could be explained if some electron neutrinos were changing into tau or muon neutrinos en route to the Earth.

$\mathrm{SNO}$, a joint venture between Canada, the United States and Britain, is a spherical vat containing 1,000 tonnes of heavy water, located two kilometres below ground in a mine some 300 kilometres north of Toronto (see Nature 411, 10-12; 2001). As currently configured, it can accurately measure the flux of electron neutrinos reaching the
The new text offers Japan an exemption from some of the restrictions controlling the effect of land-use changes on the emissions target. The move responds to Japan's claim that it is difficult for it to make cuts by other means. It has argued, for example, that it is hard for it to raise energy efficiency, because its cars and factories are already so energy efficient. Japan has little free land for new forests, but thinks that it can increase the amount of $\mathrm{CO}_{2}$ absorbed by its existing forests.

But the concessions fall short of what Japan was seeking - according to one official, they would allow a $3 \%$ cut from land-use changes, whereas Japan wanted 3.7\% — and it remains to be seen whether they will be enough to bring the country on board.

Japanese officials say that the country has not yet given up hope that the United States will ratify the protocol, and that it will not decide what to do until after talks between Prime Minister Junichiro Koizumi and US President George W. Bush later this month.

The future of the protocol has been in doubt since Bush declared in March that the United States would not ratify the treaty. But EU heads of state, after meeting with Bush in Gothenburg, Sweden, last week, confirmed that they will press ahead with ratification.

EU negotiators say that they remain confident that the Bonn talks will move the protocol forward, even without US involvement. "I would like to see the protocol ratified at the 2002 World Summit on Sustainable Development in Johannesburg,"

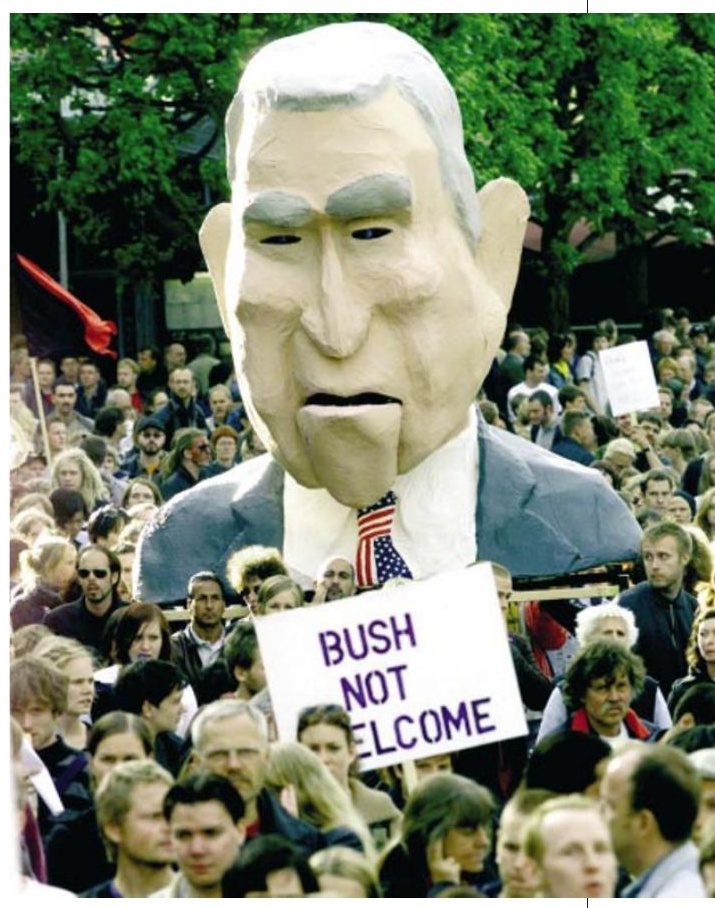

Out in the cold: protesters outside the European summit signal their anger at President Bush.

says Yvo de Boer, a member of the team of European officials that drafted the changes.

EU officials say that they hope the United States will sign up to a second agreement to cover emissions in the period after 2012. Talks on this accord should begin within the next two years.

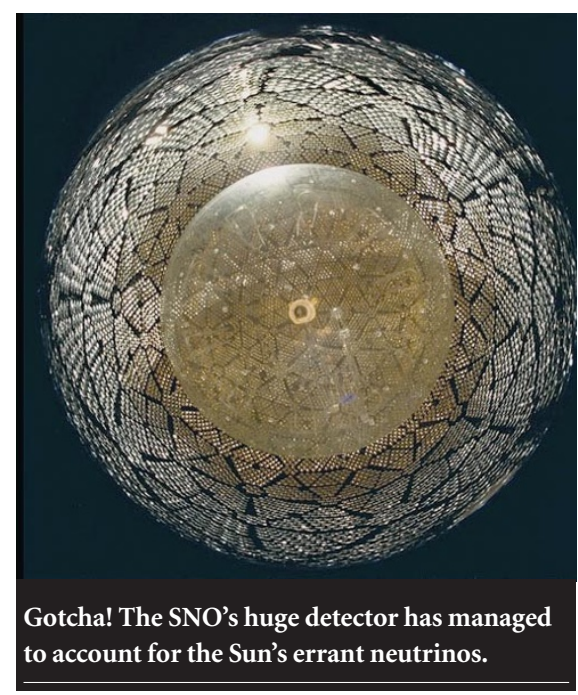

Earth. So by comparing these results with those from other detectors - which have a small sensitivity to tau and muon neutrinos — the SNO team has shown in a paper submitted to Physical Review Letters that some electron neutrinos emitted by the Sun are switching flavours.

"It's an enormous achievement," says John Bahcall of the Institute for Advanced Study in Princeton, New Jersey, who works on the solar neutrino problem. "I'm thrilled."

The result has important consequences for the standard model, the theory that describes fundamental particles and their interactions. Theorists have assumed that neutrinos have zero mass - but neutrinos must have mass if they are to switch flavours. "These results go beyond the standard model," says Art McDonald, director of SNO. "Now they have to be explained."

SNO will now be reconfigured to be sensitive to all three classes of neutrinos, providing further insights into flavour switching.
${ }^{*}$ A News and Views article on the SNO results will appear in a future issue. 